\title{
Activated cytotoxic T-lymphocyte immunotherapy is effective for advanced oral and maxillofacial cancers
}

\author{
TOMOKO OHTANI $^{*}$, YOICHI YAMADA ${ }^{1 *}$, AKIFUMI FURUHASHI ${ }^{1}$, YUKINOBU OHMURA $^{1}$, \\ SAYAKA NAKAMURA $^{1}$, HIDEFUMI KATO ${ }^{2}$, KAZUHIRO YOSHIKAWA ${ }^{3,4}$ and YOSHIAKI KAZAOKA ${ }^{1}$ \\ ${ }^{1}$ Department of Oral and Maxillofacial Surgery, ${ }^{2}$ Department of Transfusion Medicine and \\ ${ }^{3}$ Cell Therapy Center of Biochemistry, Aichi Medical University School of Medicine; \\ ${ }^{4}$ Division of Advanced Medicine, Advanced Medical Research Center, \\ Aichi Medical University, Nagakute, Aichi 480-1195, Japan
}

Received June 4, 2014; Accepted July 10, 2014

DOI: $10.3892 /$ ijo.2014.2599

\begin{abstract}
Conventional cancer treatments are surgery, radiotherapy, and chemotherapy, but treatment efficiency is insufficient and cancer recurrence is common. Immunotherapy has been added as an important cancer treatment component, but no reports on its efficacy in oral and maxillofacial cancers exist. We evaluated the clinical efficacy of adoptive immunotherapy using ex vivo-activated cytotoxic $\mathrm{T}$ lymphocytes (CTL) in the treatment of 7 patients with advanced oral and maxillofacial cancers with stage IV disease at diagnosis. The mean follow-up period was 26.2 months. Phenotype of the lymphocyte assay revealed that the percentage of $\mathrm{CD}^{+} \mathrm{T}$ cells decreased and that of $\mathrm{CD} 8^{+} \mathrm{T}$ cells increased among infused lymphocytes compared to that in unstimulated peripheral blood mononuclear cells (PBMCs), and infused lymphocytes produced a significantly higher level of IFN- $\gamma$ than PBMCs or tumor cells alone. In a representative patient who refused surgery tumor regression was confirmed after CTL infusion. Computed tomography clearly indicated a significant reduction in tumor size followed by the complete disappearance of the tumor. Histological examination showed that the cancers in patients receiving CTL therapy were heavily infiltrated with lymphocytes. The other 2 patients who received CTL therapy as adjuvant therapy showed neither recurrent disease nor new disease lesions. The 1-year survival rates showing response and those with progressive disease were 100 and
\end{abstract}

Correspondence to: Dr Yoichi Yamada, Aichi Medical University School of Medicine, 1-1 Yazakokarimata, Nagakute, Aichi 480-1195, Japan

E-mail: yyamada@aichi-med-u.ac.jp

E-mail: yyamada0925@gmail.com

*Contributed equally

Key words: oral cancer, quality of life, adoptive immunotherapy, cytotoxic T-lymphocytes, treatment outcome
$25 \%$, respectively. Moreover, no significant adverse reactions were reported during the study period. CTL therapy remains in the early stages of treatment options, but it has potential as a valuable treatment and improvement of quality of life for patients with otherwise incurable cancers.

\section{Introduction}

Cancer incurs significant morbidity and mortality, with $>6$ million deaths occurring each year worldwide (1). Until recently, cancer treatment was a 3-pronged approach, comprising surgery, radiation therapy, and chemotherapy (2). However, cancer treatment efficacy is frequently inadequate and disease is often recurrent, and in such cases, virtually all patients eventually succumb to the disease. Patients with recurrent or metastatic disease are generally incurable and are not eligible for multimodal curative treatment. The goals of cancer treatment are prolongation of overall survival, palliation of existing symptoms, prevention of new cancerrelated symptoms, and improvement in the quality of life (3). Therefore, the development of new and effective therapeutic strategies of cancer is necessary.

In the past 25 years, immunotherapy has been added as an important component of cancer treatment and is expected to provide a new strategy for cancer therapy (2). Rosenberg et al (4) introduced lymphokine-activated killer cell (LAK) therapy as a form of immunotherapy, but frequent adverse reactions to those cells activated with IL-2 were found and an adequate clinical effect was not achieved, resulting in a decrease in favor for the LAK therapy $(5,6)$. Recently, it has become widely accepted that cytotoxic T lymphocytes (CTL), originally isolated from tumor-infiltrating lymphocytes (TILs) in vitro (7), play a major role in tumor rejection in vivo (8). This approach involves stimulation of $\mathrm{T}$ lymphocytes with a specific tumor antigen in vitro. It is known that lymphocytes rapidly express and secrete cytokines after stimulation with appropriate antigens, and the quantity of IFN- $\gamma$ produced indicates the reactivity of lymphocytes for tumor cells (9). The number of tumor-specific $\mathrm{T}$ cells may also be enhanced by repetitive stimulation with autologous tumor cells or antigen in vitro. The immune system recognizes tumors, but the tumor 


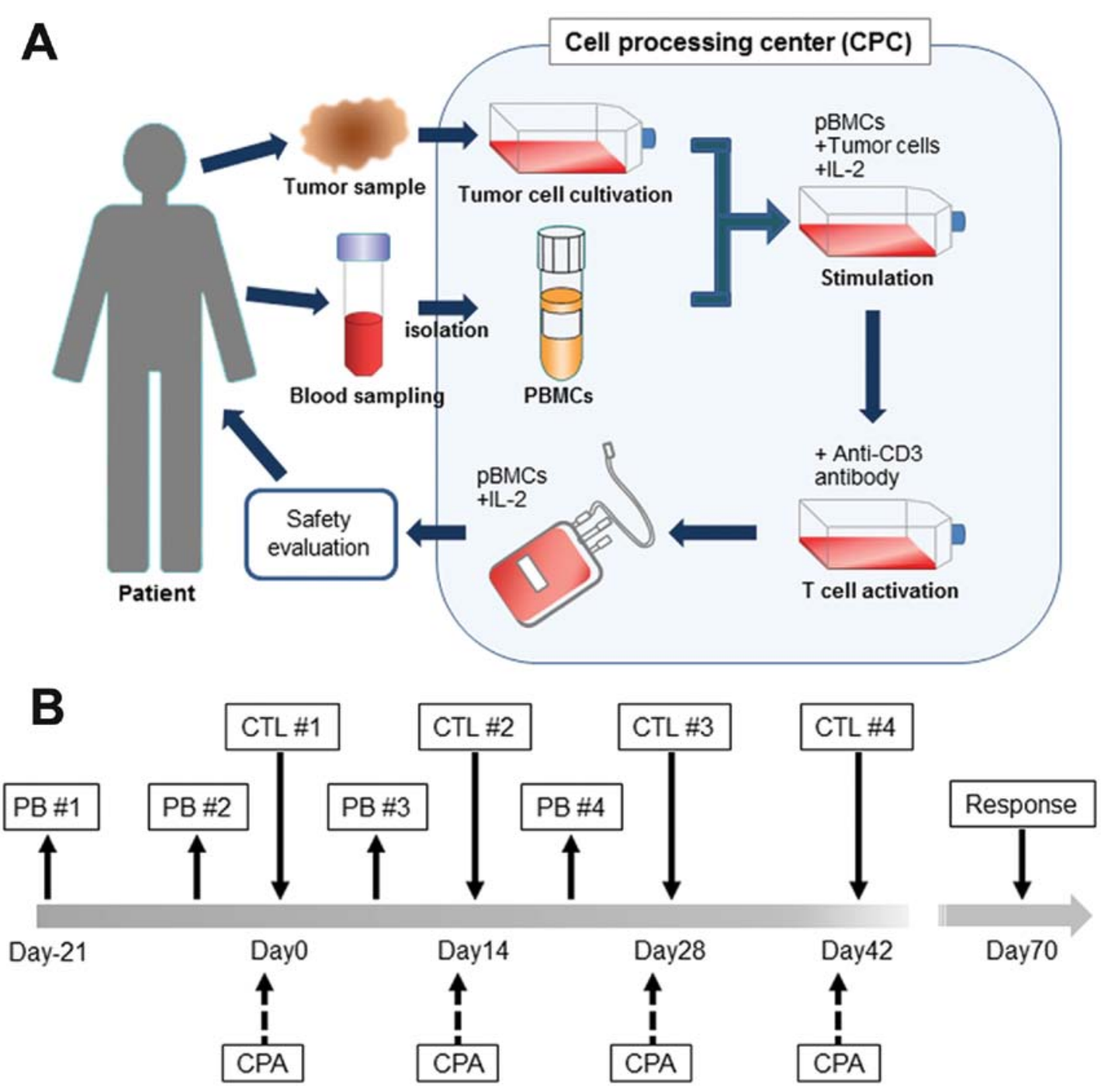

Figure 1. Treatment protocol of cytotoxic T lymphocyte (CTL) treatment. (A) The schema of CTL preparation. (B) Treatment schedule. PB, peripheral blood sampling; CPA, cyclophosphamide.

microenvironment generates immunosuppressive cells leading to immune evasion of cancer. The approach to overcoming the immunosuppressive tumor microenvironment is to generate cells in vitro that will kill tumor cells. Cellular immunotherapy, in the form of CTL, has been successfully used to treat virus-associated malignancies, some hematological malignancies, and some solid tumors (10-12). Antigen-specific $\mathrm{CD}^{+} \mathrm{T}$ cell clones have also been shown to be effective for treating malignant disease (13), implying T-cell specificity to tumor cell antigens.

Oropharyngeal cancer is the eighth most common cancer worldwide with over 145,500 deaths occurring every year (14). It is widely known that lymph node metastasis occurs at a high frequency because of the rich lymphatic submucosal plexus of the oropharynx, resulting in decreased survival rates. Although the conventional treatment for oral and maxillofacial cancers is surgery, radiotherapy, and chemotherapy, surgical treatment can often lead to severe morbidity and decreased quality of life. Chemotherapy is also widely used in cases of oral cancer, but the effects are limited because of lack of selectivity, narrow therapeutic margins, and the high prevalence of drug resistance (14). As a result, new therapeutic options for oral and maxillofacial cancers are urgently required. However, no studies on the use of immunotherapy in oral and maxillofacial cancers have been reported to date.

In this study, we applied ex vivo stimulation of CTL using irradiated tumor cells, which were used in an attempt to augment host immunological response, to generate killer cells for adoptive immunotherapy. Then, we investigated the clinical effects of CTL therapy in advanced oral and maxillofacial cancers.

\section{Materials and methods}

Study entry criteria and patients. Patients were eligible for this study if they had oral and maxillofacial cancers; a clinical performance status of 0,1 , or 2 ; if their tumor could be obtained for the CTL treatment and was positive for HLA class I antibody. Patients were excluded from participation if they were positive for hepatitis B or C antigens or for HIV antibodies. Seven patients aged between 59 and 79 years (mean age, 68.4 years) were enrolled in this study. This study was approved by the Ethics Committee of Aichi Medical University and written informed consent was obtained from all the patients. 
Table I. Patient characteristics and clinical summary.

\begin{tabular}{|c|c|c|c|c|c|c|c|c|}
\hline $\begin{array}{l}\text { Patient } \\
\text { no. }\end{array}$ & $\begin{array}{c}\text { Age } \\
\text { (years) }\end{array}$ & Sex & Disease site & $\begin{array}{l}\text { Diagnosis } \\
\text { (stage) }\end{array}$ & $\begin{array}{l}\text { Previous } \\
\text { treatments }\end{array}$ & $\begin{array}{l}\text { Total no. of } \\
\text { injected cells } \\
\times 10^{9} \text { (total no. } \\
\text { of injections) }\end{array}$ & $\begin{array}{l}\text { Cyclophosphamide } \\
\left(\mathrm{mg} / \mathrm{mm}^{2}\right)\end{array}$ & $\begin{array}{c}\text { Observation } \\
\text { periods } \\
\text { (months) }\end{array}$ \\
\hline 1 & 69 & M & $\begin{array}{l}\text { Floor of the oral } \\
\text { cavity }\end{array}$ & SCC (IV) & RT, chemo & $29.4(20)$ & 129 & 46 \\
\hline 2 & 79 & $\mathrm{M}$ & Mandible gingiva & $\begin{array}{l}\text { Malignant } \\
\text { melanoma (IV) }\end{array}$ & Surgery & $7.16(4)$ & 129 & 60 \\
\hline 3 & 66 & M & Maxillary gingiva & SCC (IV) & $\begin{array}{l}\text { RT, chemo, } \\
\text { surgery }\end{array}$ & $4.12(4)$ & 119.8 & 0.5 \\
\hline 4 & 65 & M & $\begin{array}{l}\text { Oropharynx, } \\
\text { buccal mucosa, } \\
\text { maxillary gingiva }\end{array}$ & SCC (IV) & $\begin{array}{l}\text { RT, chemo, } \\
\text { surgery }\end{array}$ & $6.4(4)$ & 127.4 & 3 \\
\hline 5 & 59 & $\mathrm{~F}$ & Tongue & SCC (IV) & $\begin{array}{l}\text { RT, chemo, } \\
\text { surgery }\end{array}$ & $6.5(4)$ & 135.1 & 58 \\
\hline 6 & 72 & $\mathrm{M}$ & Tongue & SCC (IV) & Surgery & $5.38(4)$ & 126.6 & 14 \\
\hline 7 & 69 & $\mathrm{~F}$ & Maxillary gingiva & $\begin{array}{l}\text { Spindle cell } \\
\text { sarcoma (IV) }\end{array}$ & $\begin{array}{l}\text { Chemo, } \\
\text { surgery }\end{array}$ & $10(4)$ & 155 & 2 \\
\hline
\end{tabular}

SCC, squamous cell carcinoma; RT, radiotherapy; chemo, chemotherapy.

Preparation of cells. Tumor samples used for the stimulation of peripheral blood mononuclear cells (PBMCs) were obtained from each patient and incubated for $1 \mathrm{~h}$ in RPMI-1640 (Nipro, Japan) containing 1,250 U/ml penicillin, 1,250 $\mu \mathrm{g} / \mathrm{ml}$ streptomycin and $31.25 \mu \mathrm{g} / \mathrm{ml}$ amphotericin $\mathrm{B}$, after which they were minced and enzymatically digested with $2 \%$ collagenase for $1 \mathrm{~h}$ at $37^{\circ} \mathrm{C}$ in $5 \% \mathrm{CO}_{2}$ in an incubator. The tumor cells were cryopreserved at $-152^{\circ} \mathrm{C}$ until they were used for stimulation.

Peripheral blood samples $(40 \mathrm{ml})$ were collected from the patients and PBMCs were obtained by the gradient method using Lymphosepar I (Immuno-Biological Laboratories Co., Ltd., Fujioka, Gunma, Japan). PBMCs were incubated with TIL-Medium I (Immuno-Biological Laboratories Co., Ltd.) containing $2.5 \%$ autologous plasma, $50 \mathrm{U} / \mathrm{ml} \mathrm{IL-2} \mathrm{(Shionogi}$ \& Co., Ltd., Osaka, Japan), and tumor cells irradiated for 4-5 days (Fig. 1A). PBMCs stimulated with tumor cells and IL-2 were then cultured in an anti-CD3 antibody (Janssen Pharmaceutical, Tokyo, Japan)-coated flask for 4-6 days to activate the T cells. At the end of this period, PBMCs were transferred into a culture bag (GT-T610 culture bag, KB0001, Takara Bio Inc., Otsu, Shiga, Japan) and cultured with GT-T503 culture medium (KB503S, Takara Bio Inc.) containing $2.5 \%$ autologous plasma and $50 \mathrm{U} / \mathrm{ml}$ IL-2 for 10-12 days before use for CTL therapy. The safety of the PBMCs was examined using the BD BACTEC ${ }^{\text {тм }}$ System (Becton-Dickinson and Company, Tokyo, Japan), MycoAlert ${ }^{\mathrm{TM}}$ (Eidia, Ibaraki, Japan), and Endosafe-PTS (Wako, Japan).

Treatment schedule. Four infusions of CTL, scheduled at 2-week intervals, constituted 1 cycle and were administered intravenously (Fig. 1B). Before CTL infusion, all patients received cyclophosphamide at a dose of $200 \mathrm{mg} /$ body (Shionogii \& Co., Ltd) to inhibit the activity of regulatory T cells. Patient response was assessed using computed tomography $(\mathrm{CT})$ and physical examination, on the basis of Response Evaluation Criteria in Solid Tumors (RECIST) guidelines.

Phenotype assays. Phenotype analysis of infused lymphocytes as CTL was analyzed by flow cytometry analysis with a cytomics FC500 (Beckman Coulter, Inc., Brea, CA, USA). Cultured cells were stained with anti-CD2/anti-CD20 (T11-RD1/B1-FITC, 6603928, Beckman Coulter, Inc.), anti-CD4/anti-CD8 (T4-RD1/T8-FITC, 6603802, Beckman Coulter, Inc.) and anti-CD56 (CD56-PE, N901, A07788, Beckman Coulter, Inc.) according to the manufacturer's instructions.

IFN- $\gamma$ released from CTL in response to autologous tumor cells was analyzed according to a previously reported method (15). Briefly, CTL were incubated with tumor cells overnight at $37^{\circ} \mathrm{C}$ in $5 \% \mathrm{CO}_{2}$. The supernatants were collected and the amount of IFN- $\gamma$ was measured using an ELISA kit (Human IFN- $\gamma$ ELISA Ready-Set-Go, 88-7316-88, eBioscience Inc., San Diego, CA, USA) according to the manufacturer's instructions.

\section{Results}

Patient characteristics. A total of 44 T-cell infusions were administered to 7 patients (5 males and 2 females) diagnosed with oral and maxillofacial cancers (Table I). Five patients had squamous cell carcinoma (SCC), 1 patient had malignant melanoma, and the remaining patient had spindle cell sarcoma. All 


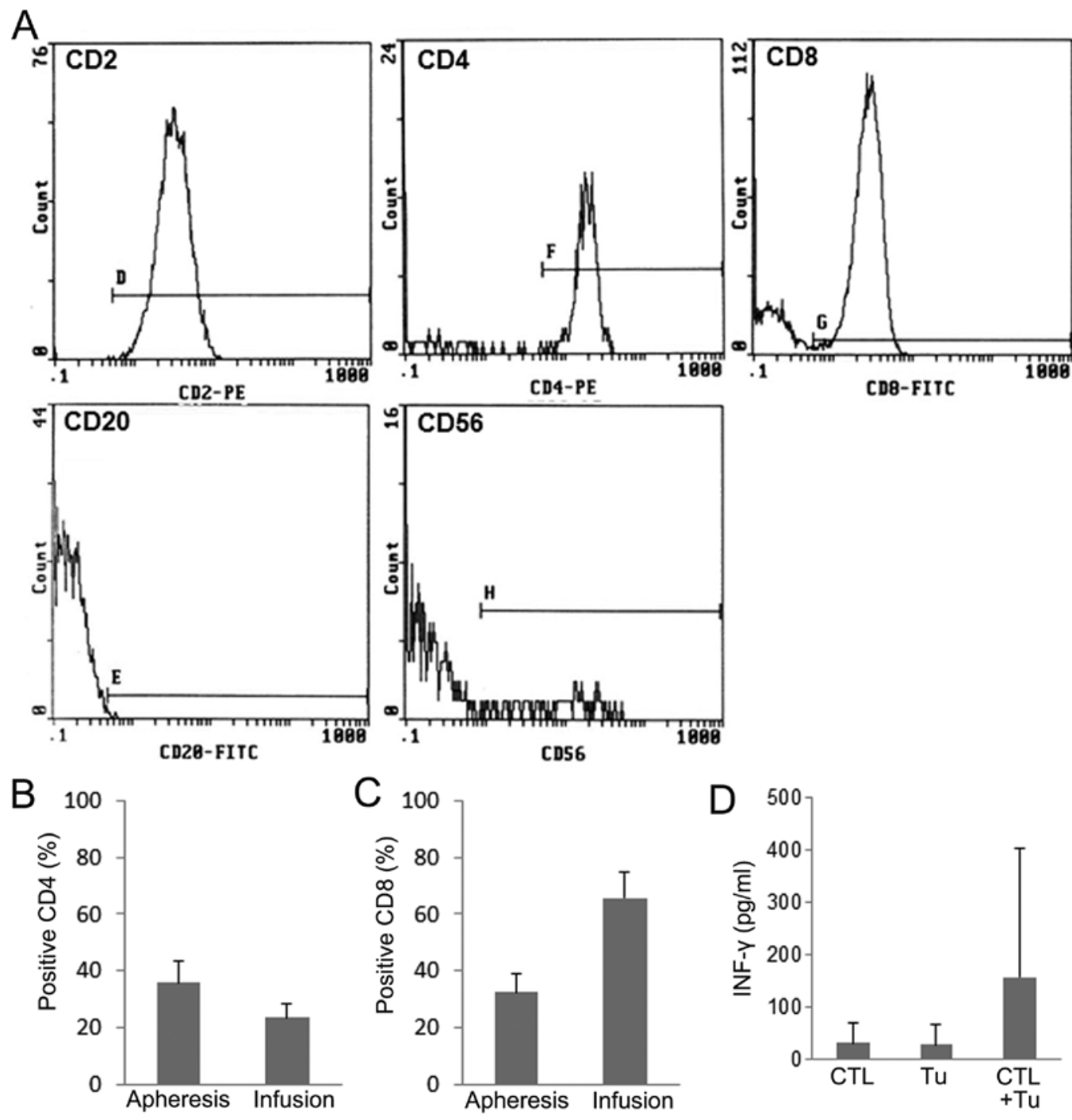

Figure 2. Characteristics of cytotoxic T lymphocytes (CTL). (A) Results of typical flow cytometric analysis for expression of surface markers (CD2, CD4, CD8, CD20 and CD56) by CTL before infusion. (B and C) Changes in surface marker expression of helper T cells (CD4) and cytotoxic T cells (CD8) before stimulation (apheresis) and after stimulation (infusion). Data shown in the bar graph are the means \pm standard deviation. (D) CTL activity, assessed by production of IFN- $\gamma$ was measured. Tu, tumor cells.

patients presented with stage IV disease at diagnosis. Tumor cells from these patients expressed HLA class I antigen by the means of immunostaining, indicating that tumor antigens could be recognized by CTL (data not shown). All patients had received prior treatment, including chemotherapy, radiotherapy, or surgery. In 5 cases (cases 1, 3, 4, 6 and 7), because the patients did not respond to previous conventional therapy, they were switched to CTL therapy. Two patients (cases 2 and 5) received CTL therapy as adjuvant therapy.

Characteristics and activity of CTL. To characterize CTL, surface markers were analyzed. CTL were mostly positive for CD2 $(99.3 \pm 0.3 \%)$, and partially positive for CD56 $(10.9 \pm 11.1 \%)$ (Fig. 2A). The expression of CD4, the marker of helper T cells in CTL, decreased to $23.6 \pm 4.5 \%$, whereas that in peripheral blood mononuclear cells (PBMCs) before stimula-

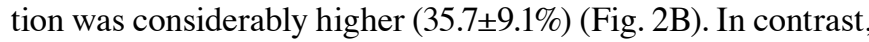
the expression of $\mathrm{CD} 8$, the marker of cytotoxic $\mathrm{T}$ cells, in CTL increased from $32.5 \pm 6.5$ to $65.6 \pm 9.3 \%$ after stimulation (Fig. 2C). The activity of PBMCs stimulated with autologous tumor cells and IL-2 (CTL) was assessed by measuring IFN- $\gamma$ production (Fig. 2D). CTL produced a significantly higher level of IFN- $\gamma$ than unstimulated PBMCs or tumor cells alone (Tu).

Clinical results. The total number of administered cells per patient ranged from $4.12-29.4 \times 10^{9}$ cells. The mean dose of cyclophosphamide received was $131.7 \mathrm{mg} / \mathrm{mm}^{2}$ body surface area (range, $119.8-155 \mathrm{mg} / \mathrm{mm}^{2}$ body surface area). The mean observation period was 26.2 months (range, 0.5-60 months).

The representative patient (case 1 in Table I) attaining CR had SCC of the floor of the oral cavity (T4N2cM0, stage IV) with lymph node metastases at diagnosis. The patient had been treated with radiotherapy and chemotherapy, but the disease was refractory. The patient refused surgery, but chose CTL treatment because of the high degree of invasiveness and the treatment burden necessitating resection as far as the skin, including resection of most of the mandible (Fig. 3A, B, E and F). First, the lymph node metastatic lesions were resected before CTL treatment, after which CTL infu- 

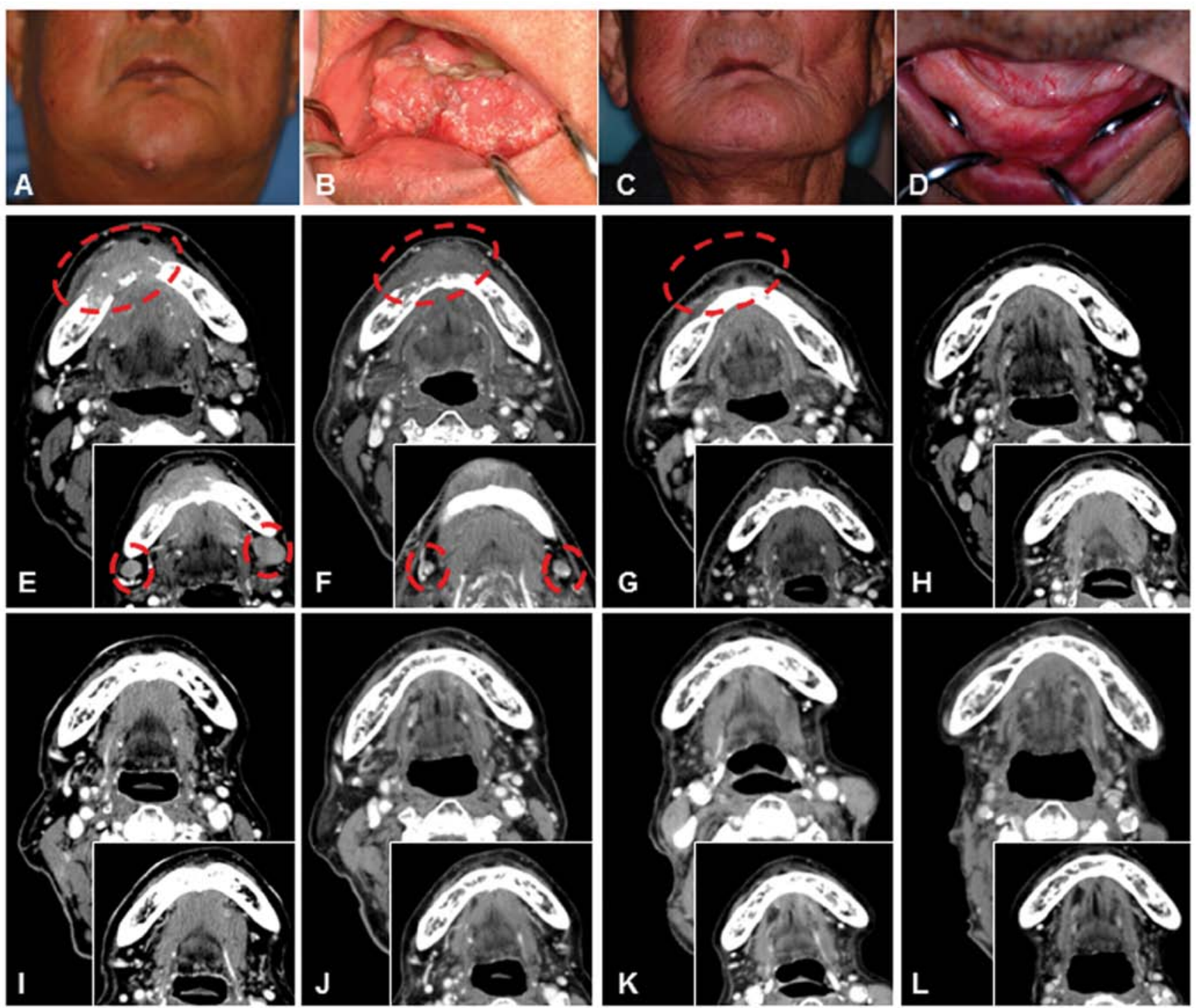

Figure 3. Clinical outcomes in a representative patient (case 1). (A and B) Extraoral and intraoral findings of the patient before treatment. (C and D) Extraoral and intraoral findings 44 months later, after 5 cycles of treatment. (E-L) Computed tomograpy image taken at diagnosis (E), after radiotherapy and chemotherapy $(\mathrm{F})$, after 2 cycles $(\mathrm{G}), 4$ cycles $(\mathrm{H})$, and 5 cycles of cytotoxic T lymphocyte treatment (I), 10 months (J), 36 months (K), and 46 months (L) after the final cycle of treatment.
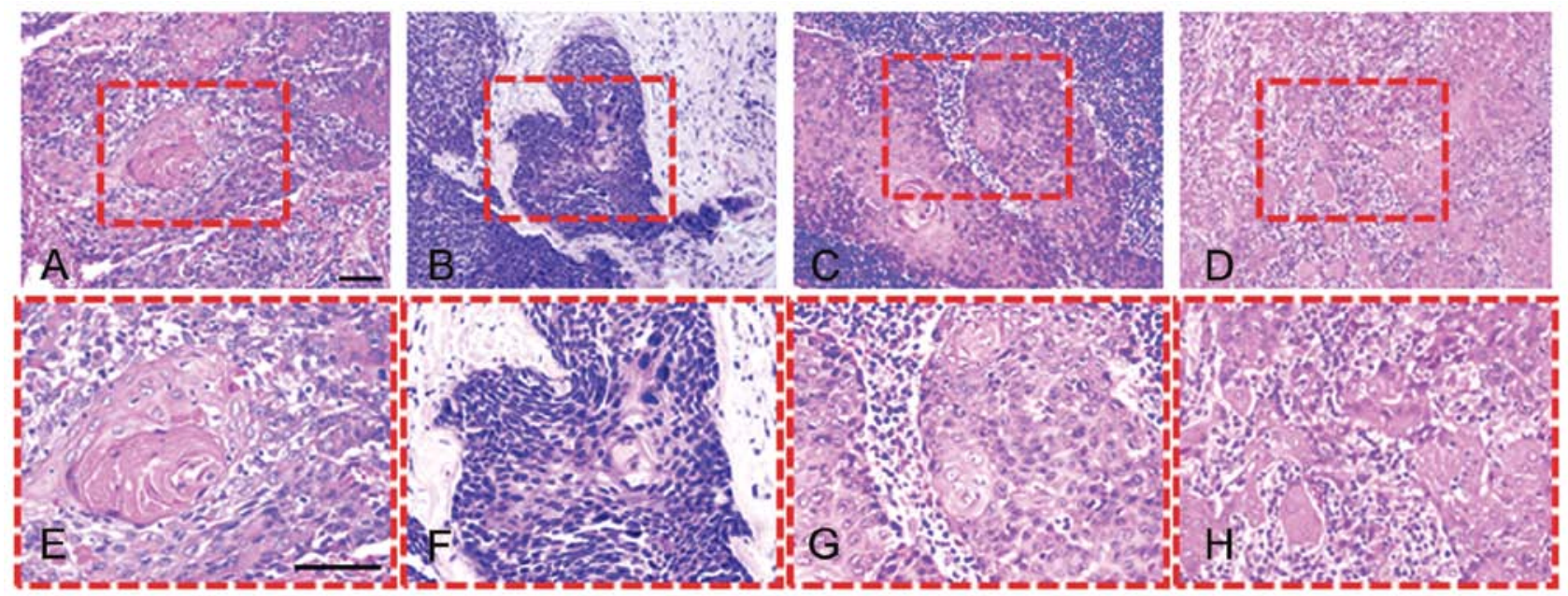

Figure 4. Representative histological images of biopsy samples. (A-D) Biopsy samples were analyzed by hematoxylin and eosin staining. (E-H) Higher magnification images of (A-D). (A and E) Well-differentiated squamous cell carcinoma cells were seen before treatment. (B and F) After chemoradiotherapy, residual cancer cells and irregular chromatin was observed. (C and G) Lymph node biopsy prior to the 1st infusion. (D and H) After 4 cycles of cytotoxic T lymphocyte treatment, tumors were infiltrated with lymphocytes. Scale bar, $50 \mu \mathrm{m}$. 


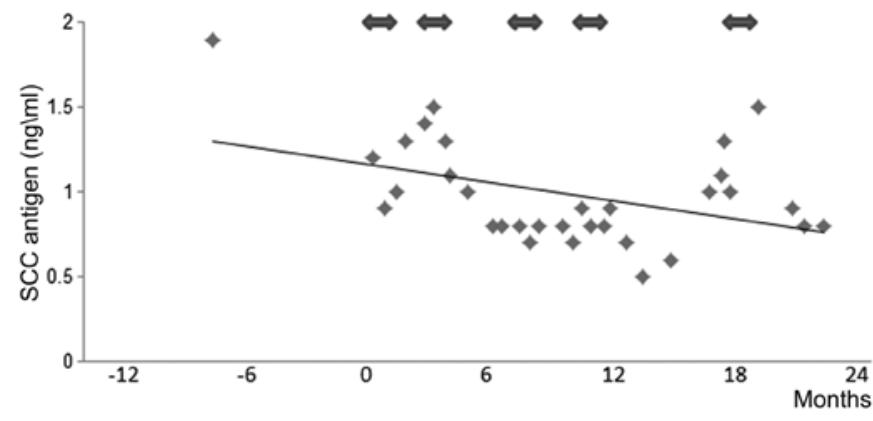

Figure 5. Changes in the serum SCC antigen. The arrows indicate the times of cytotoxic T lymphocyte treatments.

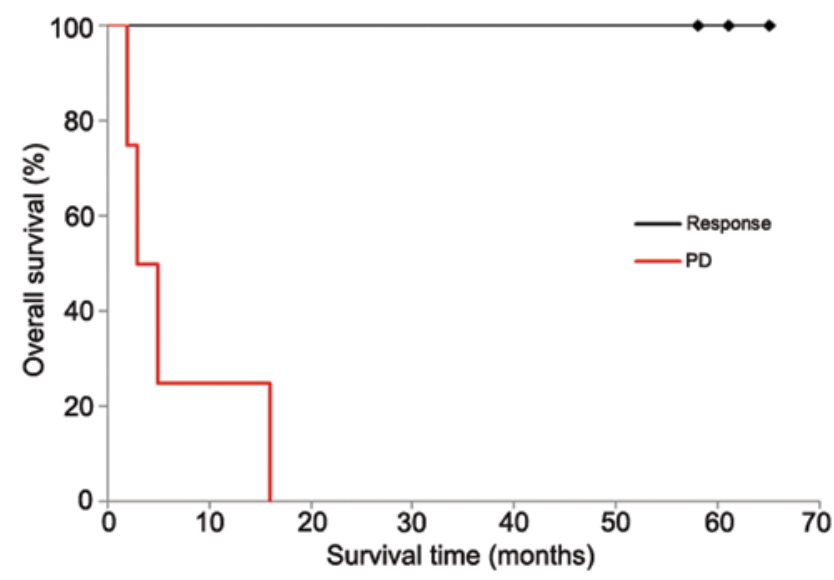

Figure 6. Patient survival data. Kaplan-Meier plot showing the duration of survival of patients treated with cytotoxic T lymphocytes. Dots indicate patients who are still alive and being followed up in the study. Response, response group, $\mathrm{PD}$, progressive disease group.

sion was performed by IVH injection after culture. After the second course of CTL infusion, the tumor size was markedly decreased (Fig. 3G). Because of the partial response, this patient received additional courses of CTL therapy at 7,11 and 18 months after the first course of CTL infusion. Computed tomography (CT) clearly indicated a significant reduction in tumor size followed by the complete disappearance of the tumor (Fig. $3 \mathrm{H}$ and I). Target lesions remained in stable CR for 46 months after the last course of CTL infusion (Fig. 3C, D and J-L). Histological examination of clinical biopsy samples showed well-differentiated SCC cells with individual cell keratinization and formation of cancer pearls before treatment (Fig. 4A and E). After chemoradiotherapy, residual cancer showed a wide pattern of alterations and the nuclei of residual neoplastic cells were enlarged and irregular, with clumped chromatin (Fig. 4B and F). The lymph node exenterated for the 1st cycle of CTL therapy revealed the presence of cancer cell nests (Fig. 4C and G). Tumors treated with CTL were heavily infiltrated with lymphocytes (Fig. 4D and $\mathrm{H}$ ). In addition, the SCC antigen levels decreased after CTL treatment (Fig. 5).

Two patients (cases 2 and 5) who received CTL therapy as adjuvant therapy showed neither recurrent disease nor new disease lesions during the observation period. In cases 6 and 7, the target tumor lesions resulted in stable disease (SD) after CTL treatment. The 1-year survival rates of the response group (cases 1,2 and 5) and the progressive disease (PD) group (cases 3, 4, 6 and 7) were 100 and 25\%, respectively (Fig. 6). Moreover, no significant adverse reactions were reported during the observation period.

\section{Discussion}

This study evaluated the clinical efficacy of adoptive immunotherapy using specific lymphocytes activated by irradiated autologous tumor cells, which expressed HLA class I antigen, and used as immunogens to patient PBMCs for the treatment of advanced oral and maxillofacial cancers. Our results with CTL immunotherapy in 7 patients with advanced cancers showed that adoptive cellular immunotherapy can be performed safely in such patients. Although the cells are expected to be utilized in both adoptive and active immunotherapies against cancer, the clinical efficacy of immunotherapy remains to be clarified. In a previous report, there was a tendency for CTL not to be activated from patients with low $\mathrm{CD} 8^{+}$cell populations (16). However, in this study the proportion of $\mathrm{CD} 8^{+}$cells in the CTL population was increased compared to that in the PBMCs before stimulation (Fig. 2C). Mature differentiated $\mathrm{CD}^{+} \mathrm{T}$ cells and some types of $\mathrm{CD}^{+} \mathrm{T}$ cells release IFN- $\gamma$, which enhances the immune response by upregulating the expression of MHC class I molecules on both tumor cells and tumor-resident APCs (17). Because the percentage of CD8 ${ }^{+}$ cells increased after stimulation, higher IFN- $\gamma$ production by CTL may have occurred in the patients included in this study. The successful induction of effective CTL from PBMCs may result in favorable clinical results.

Many clinical studies of adoptive immunotherapy using mostly LAK cells and TILs have shown a significant response rate in patients with melanoma and some other cancers $(17,18)$. These studies also demonstrate efficacy prior to surgery (19). However, there has been no report of a clinical study investigating CTL administration without surgery and demonstrating obvious tumor regression of advanced oral or maxillofacial cancers. To our knowledge, our report is the first to show clear evidence for the potential of the application of immunotherapy in oral and maxillofacial cancer patients. In our study, the representative patient refused surgery and instead was treated with CTL immunotherapy. Interestingly, the original tumor and lymph node metastases disappeared following CTL treatment despite the absence of surgery (Fig. 3). Histological examination showed that the efficacy of CTL treatment, as evidenced by the fact that tumors were heavily infiltrated and attacked by the activated lymphocytes (Fig. 4). In addition, a positive response to CTL led to an improvement in overall survival for patients with advanced cancer. Moreover, no significant adverse reactions were reported during the observation period. Therefore, CTL induction using autologous tumor cells as immunogens has potential anticancer efficacy in refractory oral and maxillofacial cancers.

In agreement with our findings, Khammari et al (20) reported that adoptive immunotherapy with tumor-infiltrating lymphocytes used as an adjuvant regimen for stage III melanoma was effective and both relapse-free survival and overall survival were extended. Another study revealed an apparent survival benefit for patients with resected lung cancer who received adjuvant CTL (21). It has been reported that the rate 
of local and regional recurrence of oral cancer varies from 18 to $76 \%$ according to the TNM stage and initial treatment, and recurrence has been reported in $>50 \%$ patients with advanced clinical stages (III or IV) (22). In this study, patients with stage IV at diagnosis who received CTL treatment as adjuvant therapy, continue to have a good prognosis without recurrent disease (cases 2 and 5 in Table I). These results indicate that this treatment strategy might be effective as adjuvant treatment for patients with advanced stage cancer.

In conclusion, adoptive immunotherapy using ex vivo activated CTL with irradiated autologous tumor cells has favorable clinical efficacy without side effects. Therefore, it could form a novel treatment option that lead to improvement of quality of life for advanced oral and maxillofacial cancers and may be a promising approach for targeted therapy in such patients. However, further clinical trials will be required to confirm the present findings in a large-scale prospective clinical study.

\section{Acknowledgements}

The authors wish to thank members of the Department of Oral and Maxillofacial Surgery, Motoaki Uruma in the Blood Transfusion Service Department, and Kazuo Hara in the Pathology Department, Aichi Medical University Hospital for their help, encouragement, and contributions to the completion of this study.

\section{References}

1. World Health Organization. The World Health Report 2004: Changing history. WHO, Geneva, 2004.

2. DeVita VT Jr and Rosenberg SA: Two hundred years of cancer research. N Engl J Med 366: 2207-2214, 2012.

3. Colevas AD: Chemotherapy options for patients with metastatic or recurrent squamous cell carcinoma of the head and neck. $\mathrm{J}$ Clin Oncol 10: 2644-2652, 2006.

4. Rosenberg SA, Lotze MT, Muul LM, et al: Observations on the systemic administration of autologous lymphokine-activated killer cells and recombinant interleukin-2 to patients with metastatic cancer. N Engl J Med 313: 1485-1492, 1985.

5. Ettinghausen SE, Puri RK and Rosenberg SA: Increased vascular permeability in organs mediated by the systemic administration of lymphokine-activated killer cells and recombinant interleukin-2 in mice. J Natl Cancer Inst 80: 177-188, 1988.

6. Soda H, Koda K, Yasutomi J, et al: Adoptive immunotherapy for advanced cancer patients using in vitro activated cytotoxic T lymphocytes. J Surg Oncol 72: 211-217, 1999.

7. Baxevanis CN, Dedoussis GV, Papadopoulos NG, Missitzis I, Stathopoulos GP and Papamichail M: Tumor specific cytolysis by tumor infiltrating lymphocytes in breast cancer. Cancer 74: 1275-1282, 1994.
8. Knuth A, Wolfel T and Meyer zum Buschenfelde KH: T cell responses to human malignant tumors. Cancer Surv 13: 39-52, 1992.

9. Desombere I, Meuleman P, Rigole H, et al: The interferon gamma secretion assay: a reliable tool to study interferon gamma production at the single cell level. J Immunol Methods 286: 167-185, 2004.

10. Straathof KC, Bollard CM, Popat U, et al: Treatment of nasopharyngeal carcinoma with Epstein-Barr virus-specific T lymphocytes. Blood 105: 1898-1904, 2005.

11. Marijt E, Wafelman A, van der Hoorn M, et al: Phase I/II feasibility study evaluating the generation of leukemia-reactive cytotoxic $\mathrm{T}$ lymphocyte lines for treatment of patients with relapsed leukemia after allogeneic stem cell transplantation. Haematologica 92: 72-80, 2007.

12. Toh U, Yamana H, Sueyoshi S, et al: Locoregional cellular immunotherapy for patients with advanced esophageal cancer. Clin Cancer Res 6: 4663-4673, 2000.

13. Yee C, Thompson JA, Byrd D, et al: Adoptive T cell therapy using antigen-specific $\mathrm{CD}^{+} \mathrm{T}$ cell clones for the treatment of patients with metastatic melanoma: in vivo persistence, migration, and antitumor effect of transferred T cells. Proc Natl Acad Sci USA 99: 16168-16173, 2002.

14. da Silva SD, Hier M, Mlynarek A, Kowalski LP and AlaouiJamali MA: Recurrent oral cancer: current and emerging therapeutic approaches. Front Pharmacol 3: 149, 2012.

15. Kawakami Y, Eliyahu S, Delgado $\mathrm{CH}$, et al: Cloning of the gene coding for a shared human melanoma antigen recognized by autologous T cells infiltrating into tumor. Proc Natl Acad Sci USA 91: 3515-3519, 1994.

16. Saitoh S, Kurisaka M, Mori K, Maeda N and Fujimoto S: Induction of specific cytotoxic T lymphocytes against autologous brain tumor by crossreactive allo-tumor cell stimulation. Jpn J Cancer Res 88: 289-295, 1997.

17. Restifo NP, Dudley ME and Rosenberg SA: Adoptive immunotherapy for cancer: harnessing the T cell response. Nat Rev Immunol 22: 269-281, 2012.

18. Rosenberg SA, Spiess P and Lafreniere R: A new approach to the adoptive immunotherapy of cancer with tumor-infiltrating lymphocytes. Science 233: 1318-1321, 1986.

19. Rosenberg SA, Yang JC, Sherry RM, et al: Durable complete responses in heavily pretreated patients with metastatic melanoma using T-cell transfer immunotherapy. Clin Cancer Res 17: 4550-4557, 2011

20. Khammari A, Nguyen JM, Pandolfino MC, et al: Long-term follow-up of patients treated by adoptive transfer of melanoma tumor-infiltrating lymphocytes as adjuvant therapy for stage III melanoma. Cancer Immunol Immunother 56: 1853-1860, 2007.

21. Ratto GB, Zino P, Mirabelli S, et al: A randomized trial of adoptive immunotherapy with tumor-infiltrating lymphocytes and interleukin-2 versus standard therapy in the postoperative treatment of resected nonsmall cell lung carcinoma. Cancer 78: 244-251, 1996.

22. Agra IM, Filho JG, Martins EP and Kowalski LP: Second salvage surgery for re-recurrent oral cavity and oropharynx carcinoma. Head Neck 32: 997-1002, 2010. 